\title{
Performance Improvement of Shallow Solar Pond using Nanoparticles
}

\author{
Mohammad A. Hamdan* and Lana A. Al-Qudah \\ Dept. of Mechanical Engineering, Faculty of Engineering \& Technology, The University of Jordan, Amman, Jordan
}

\begin{abstract}
Countries are going through shortage of energy source; consequently the futures are looking for alternative source of energy. A very high potential Source of alternative source of energy is solar energy. Solar pond as one way to utilize solar energy and shallow solar pond (SSP) is one type of solar pond. Shallow solar pond can be built easily and at a comparatively low cost over large space, using and storing solar energy on a grand scale. They can't pollute the air, and coupled with desalting units, they can be used to purify water. Shallow Solar ponds with nanoparticles give a great result. In this work two shallow solar ponds were constructed and installed side by side to study the effect of adding aluminum oxide $\mathrm{AL}_{2} \mathrm{O}_{3}$ nanoparticles on the performance of the ponds (one with nanoparticles , while the other one without ). It was found that the performance of the shallow solar pond in general was improved by addition of nanoparticles, with an increase in the temperature of the lower convective zone varies between $2.1^{\circ} \mathrm{C}$ to $11.3^{\circ} \mathrm{C}$, with the maximum increase is obtained when $0.2 \%$ concentration of nanoparticles.
\end{abstract}

Keywords: Shallow Solar Pond, Nanoparticles, Energy Source

\section{Introduction}

Shallow solar pond (SSP) is used to collect and store solar heat for certain applications. Salinity gradient is created within the pond by adding salt to the lower layer, this will prevent convective heat loss out of the pond. SSP are very simple to assemble and at low cost, furthermore, they are environmentally friendly and the stored heat may be used for different applications. In an attempt to enhance SSP performance, extensive research was recently conducted, among such work is the utilization of nanofluids, which are characterized by their excellent thermal performance. It is well known that the thermal conductivity and hence the thermal efficiency of thermal energy storage system will be improved by adding nanoparticles such as Aluminum and copper oxide, Khedkar et. at., (2012) Saidura, et al (2011) used water-based aluminum nanofluid to evaluated the effect of nanofluid-based absorbers on direct solar collector.

${ }^{*}$ Corresponding author

E-mail: mhamdan@ju.edu.jo

(C) 2016 International Association for Sharing Knowledge and Sustainability

DOI: $10.5383 /$ ijtee. 11.02 .002
It was found that the particle size has minimal influence on the optical properties of the nanofluid such that he extinction coefficient is found linearly proportional to the volume fraction. Taylor et al (2011) reported that more than $95 \%$ of the incident light is absorbed if the fluid depth is more than $10 \mathrm{~cm}$. when graphite nano particles are added to the fluid. They also compared the model predicted results to spectroscopic measurements results of extinction coefficients over wavelengths that are important for solar energy ( 0.25 to 2.5 $\mathrm{m})$ Yousefi, et al (2012) investigated the effect of using $\mathrm{Al}_{2} \mathrm{O}_{3}-\mathrm{H}_{2} \mathrm{O}$ as a working fluid on the performance of a flat plate solar collector, they concluded that an increase in the efficiency of the collector with a value of $28.3 \%$ when $0.2 \mathrm{wt} \%$ of $\mathrm{Al}_{2} \mathrm{O}_{3}$ was added was obtained.

Ladjevardi, et al (2013) concluded that it is possible to absorb more than $50 \%$ of the incident solar radiation when using graphite nanofluids, while pure water can only absorb around $27 \%$ of the incident radiation. M.A. Al-Nimr, and Al-Dafaie (2014) developed and solved a mathematical model that describes the thermal performance for a two-layer nanofluid 
solar pond. The upper layer is made of mineral oil and the lower layer is made of nanofluid.

They verified that using nanofluid will increase the extinction coefficient of the lower layer and consequently will improve the thermal efficiency and the storage capacity of the pond. In this work, In this work two shallow solar ponds were constructed and installed side by side to study the effect of adding aluminum oxide $\mathrm{AL}_{2} \mathrm{O}_{3}$ nanoparticles on the performance of the ponds.

\section{Experimental Setup and Procedure}

The main component of the experimental setup used in this work is the soar still, which is shown in Figure 1. As shown in this Figure the shallow solar pond consists of Galvanized steel outer surface with base area of $(80 \mathrm{~cm} \mathrm{x} 80 \mathrm{~cm})$, with height of $45 \mathrm{~cm}$ and thickness of $8 \mathrm{~cm}$, and steel inner surface with base area of $(69.7 \mathrm{~cm} \mathrm{X} 69.7 \mathrm{~cm})$ with $39.8 \mathrm{~cm}$ height and $12 \mathrm{~cm}$ thickness, and it was coating with powder coating paint (PE) Polyethylene which is considered an excellent adhesion to steel, sprier long term corrosion resistance and protection of the steel. The shallow solar pond is insulated by a rock wool of 5 $\mathrm{cm}$ thickness

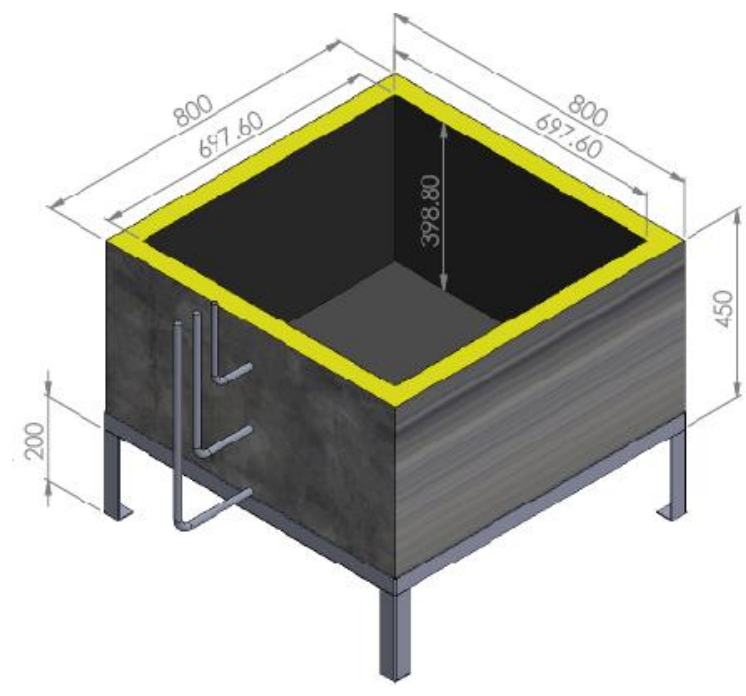

Figure 1: Schematic Diagram for Shallow Solar Pond

The second main component used is the data acquisition system, within which the process of sampling signals that measure real world physical conditions and converting the resulting samples into digital numeric values that can be manipulated by a computer. Data acquisition systems typically convert analog waveforms into digital values for processing and its applications are controlled by software programs developed using various general purpose programming languages such as LabVIEW.

\section{The components of Data Acquisition Systems} Include:

1. Sensors to convert physical parameters to electrical signals

2. Signal conditioning circuitry to convert sensor signals into a form that can be converted to digital values.

3. Analog-to-digital converters, which convert conditioned sensor signals to digital values.

The salinity percentage of shallow solar pond was measured using a refractometer, which takes advantage of the fact that light curves as it passes through changed materials. In water, the amount of bending (refraction) is related to how much salt is dissolved in the water. It gets its name from the refractive index, which is a measure of how far light is bent by different materials. When using a refractometer, a sample is placed on an optical prism in the sample window. As light gleams through the sample, it is bent according to the salinity of the water, and casts a shadow on the scale that is visible through the eye. Salinity is read directly through the eye.

Finally the incident solar radiation was measured using a pyranometer, the output of which is directly connected to the data acquisition system for storage and further analysis.

\section{Procedure}

As sated earlier, two shallow solar ponds were constructed and installed side by side. The following steps were conducted during this work:

1. Sodium chloride $(\mathrm{NaCl})$ salt was added to each pond to make up a salinity gradient along the height of the pond. The salinity gradient was varied from a maximum value of $25 \%$ within the $\mathrm{LCZ}$ to almost zero at the surface of the pond. Refractometer was used to measure the salinity percentage in water

2. A known quantity of $\mathrm{Al}_{2} \mathrm{O}_{3}$ nanoparticles was add in a horizontal direction into the $\mathrm{LCZ}$ of pond such that the stability of the pond will not be affected.

3. The temperature at different locations within the two ponds were recorded using thermocouples (Type-K) which are fed into a data acquisition system to record the temperatures on hourly basis.

4. In addition to the temperature within the two ponds, the hourly solar radiation was recorded by the weather station.

5. The same procedure was followed for different nanoparticles concentration within the pond. These concentration are $0.1,0.2,0.3,0.4,0.5,0.6$, and $0.8 \%$.

\section{Results}

The hourly global solar radiation on the typical days of experimental work is shown in the Figure 2. As indicated in this Figure the solar radiation increases in the morning to a maximum value at noon, beyond which is starts to decrease to almost zero value in the evening. 


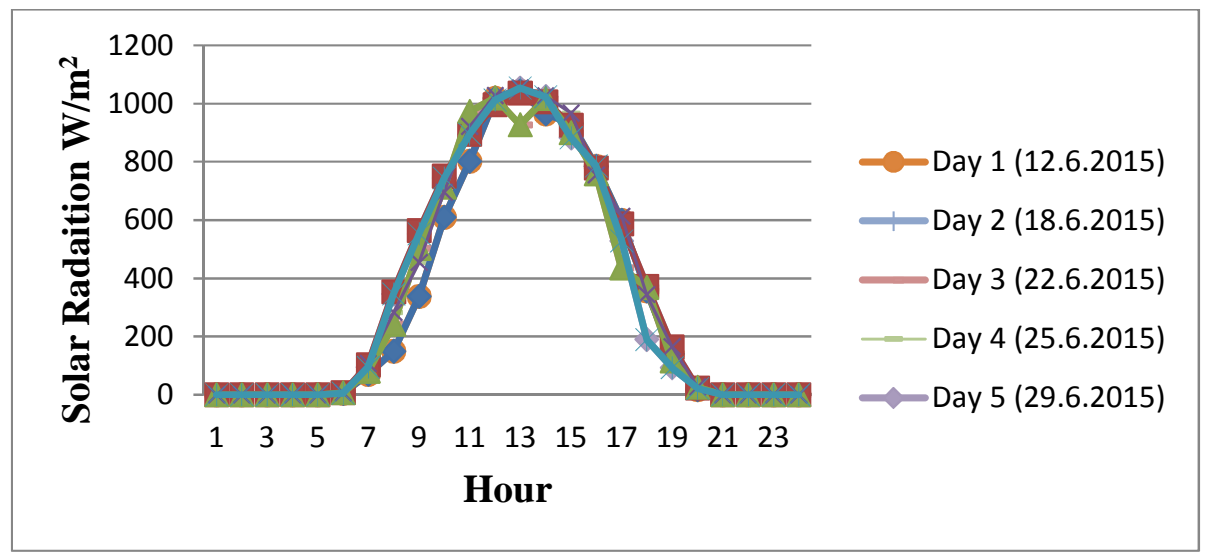

Figure 2: Variation of Irradiance with Time of the Days Observed During Days of the Experiment

Figures (3), through (9) show the hourly temperature within the lower convective zone (LCZ) of the pond with different concentration of nanoparticles and without nanoparticles and it also shown the ambient temperature. It may be observed from these Figures that the nanoparticles have the potential to increase the temp of LCZ. This is due to the fact that nanoparticles increase the thermal conductivity of the Nano fluid leading to enhance the amount of heat that is stored in the water. As indicated in these in these Figures the LCZ temperature start to increase in the early hours of daytime to maximum values at noon. Then the temperature starts to decrease to the lowest values in the next morning. Noting that the temperature at midnight exceeds that in the morning, this is due to the high heating capacity of water and hence the amount of stored heat within it.

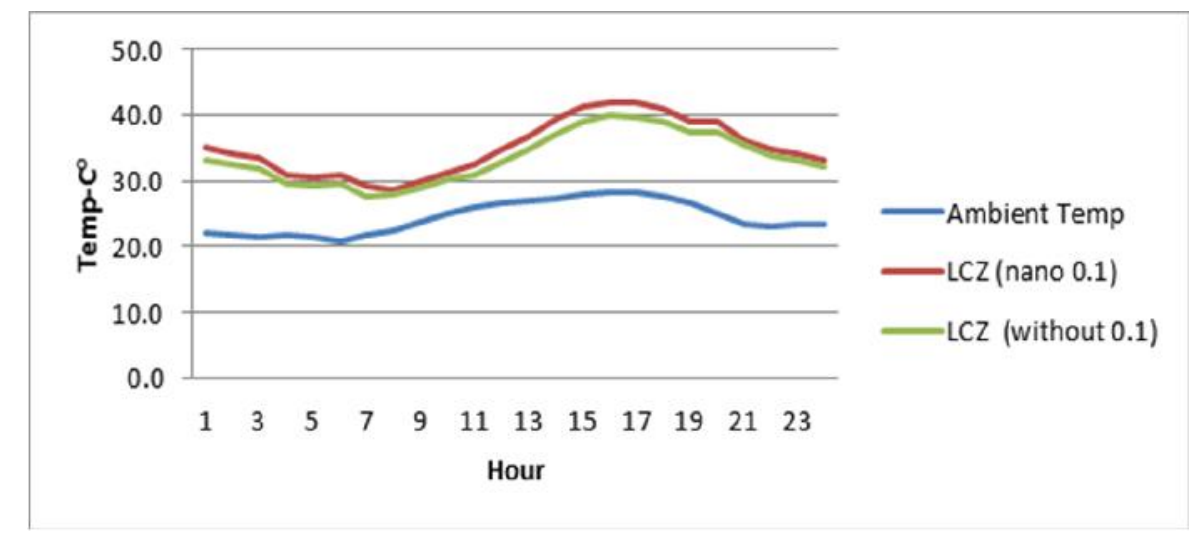

Figure 3: Hourly Temperature (Day 10.6.2015)

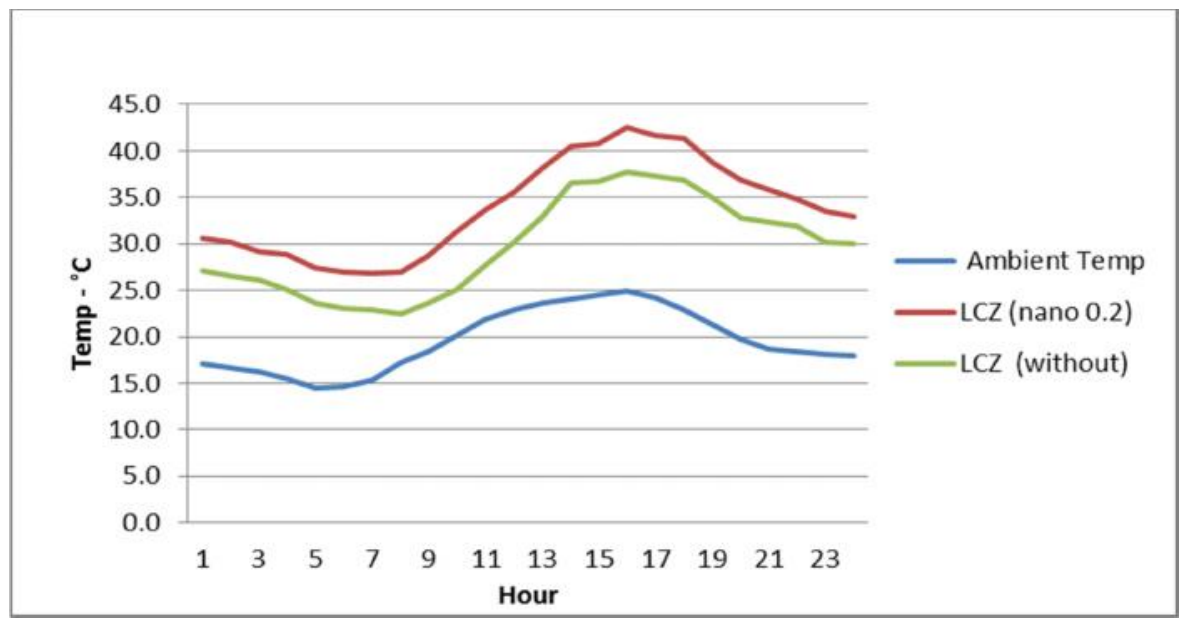

Figure 4: Hourly Temperature (C 12.6.2015) 


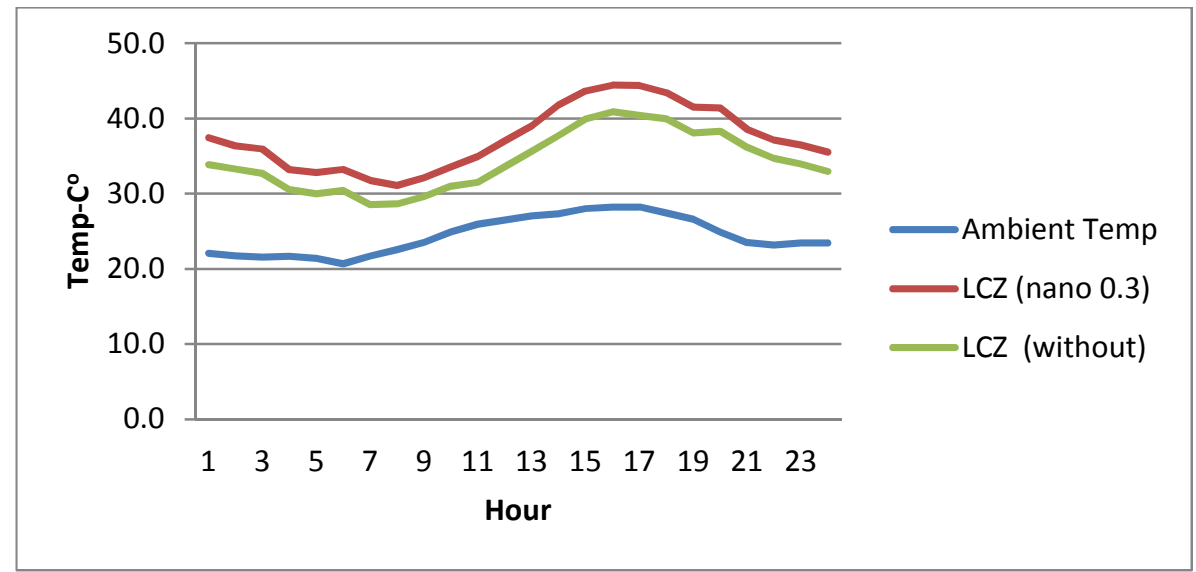

Figure 5: Hourly Temperature (Day 15.6.2015)

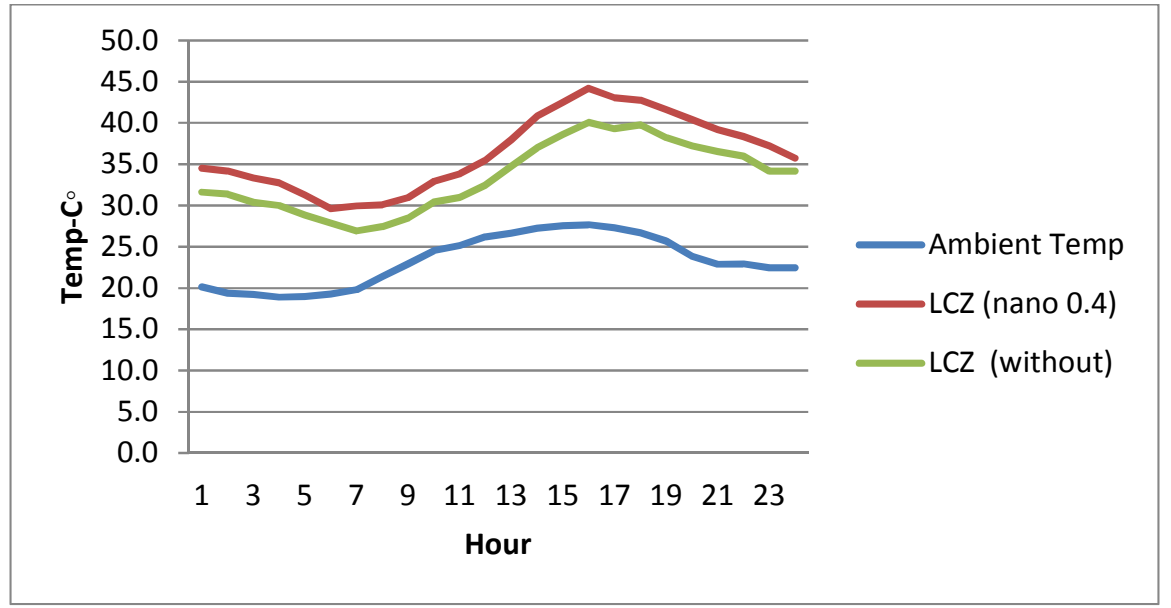

Figure 6: Hourly Temperature (Day 18.6.2015)

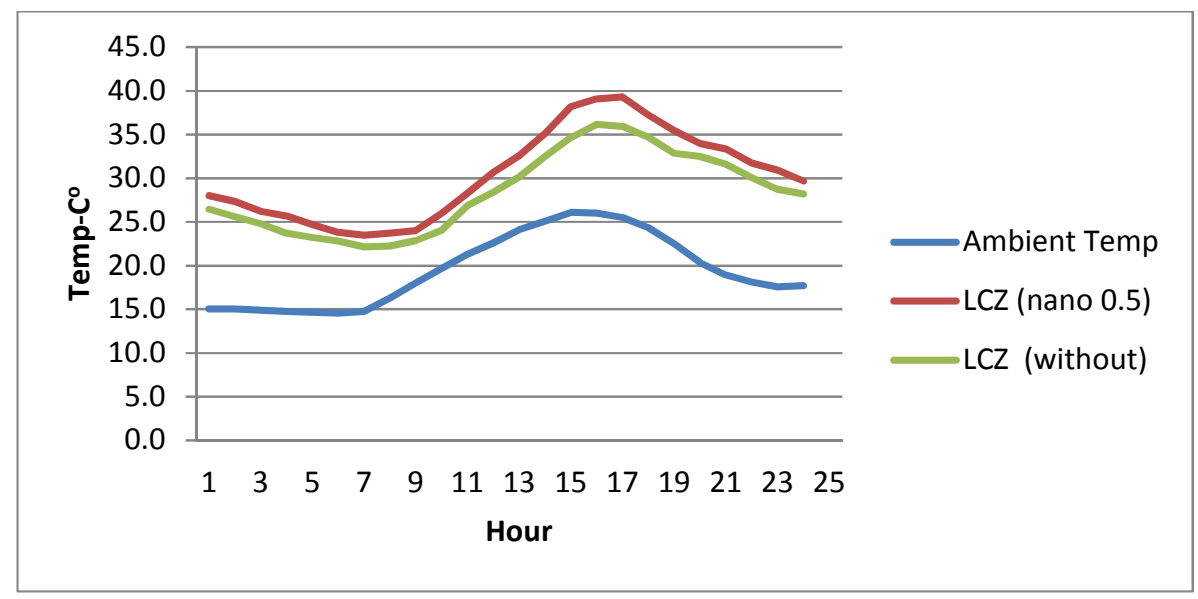

Figure 7: Hourly Temperature (Day 20.6.2015) 


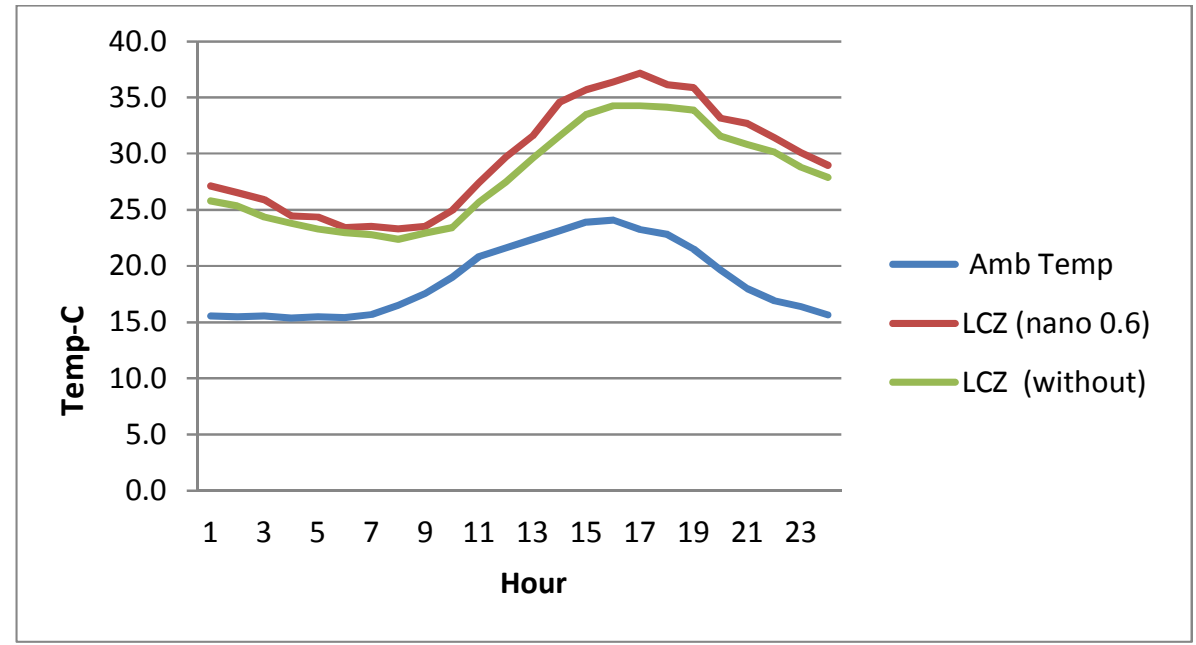

Figure 8: Hourly Temperature (Day 22.6.2015)

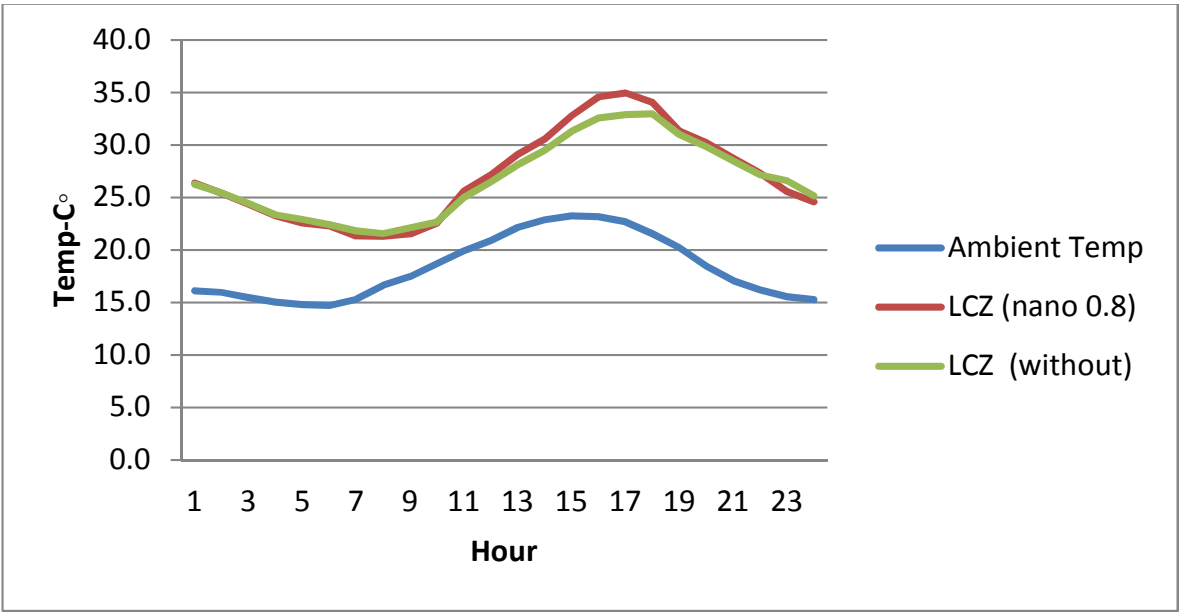

Figure 9: Hourly Temperature (Day 25.6.2015)

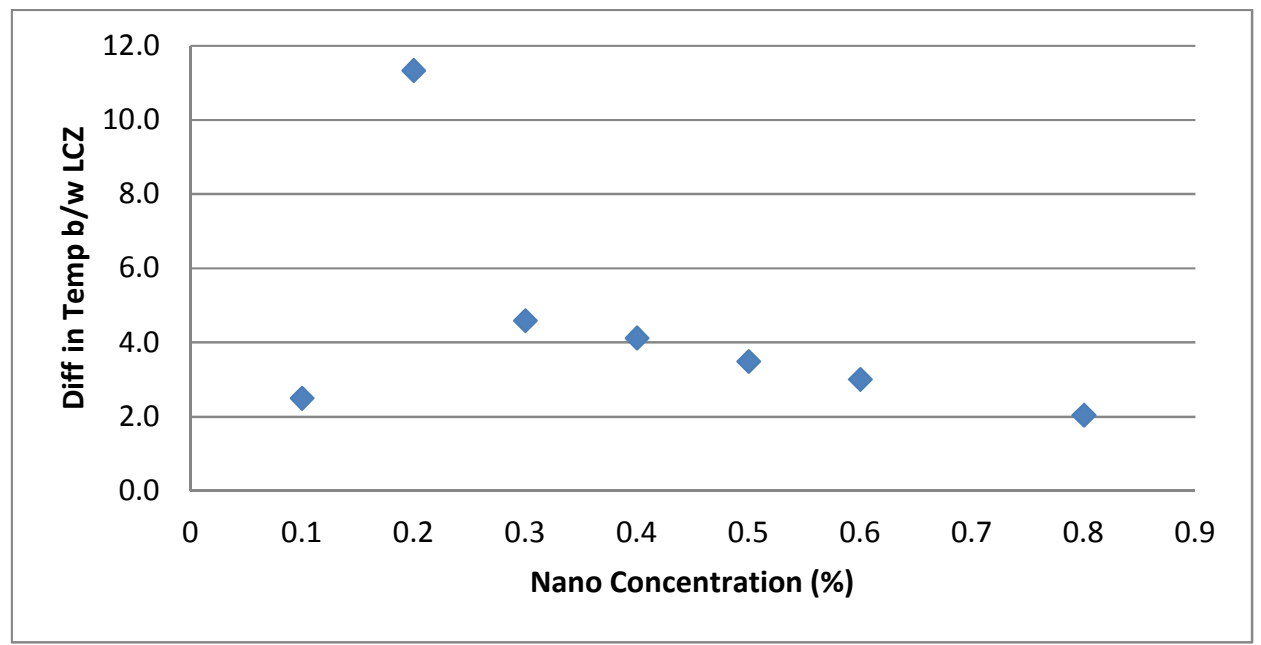

Figure 10 : Difference in Temperature with Difference Nanoparticles Concentration 
Furthermore it may be noted that the temperature within LCZ exceed that of the ambient temperature, while the temperature of LCZ that contain nanoparticles exceeds the case when the LCZ doesn't. As indicated the increase in the temperature of the $\mathrm{LCZ}$ when nanoparticles are used vary from $2.1^{\circ} \mathrm{C}$ to 11.3 ${ }^{\circ} \mathrm{C}$, and that is achieved when $0.2 \%$ concentration of nanoparticles is used. This is well illustrated in Figure (10).

\section{Conclusion}

In the experimental work, two shallow solar ponds were designed, constructed and operated to investigate the effect of Aluminum oxide nanoparticles addition with variable concentration to the $\mathrm{LCZ}$ of the pond on the performance of the pond. It may be concluded that shallow solar pond have potential for storing solar thermal energy. This potential becomes more significant when Aluminum oxide $\mathrm{Al}_{2} \mathrm{O}_{3}$ was added with different amounts. Finally it may be concluded that the most optimum concentration of nanoparticles added was $0.2 \%$.

\section{References}

[1] Khedkar R.S, Sonawane S.S, and Wasewar K.L, (2012). Influence of $\mathrm{CuO}$ nanoparticles in enhancing the thermal conductivity of water and monoethylene glycol based nanofluids. Int Commun Heat Mass Transf; 39:665-9.
[2] Ladjevardi S.M, Asnaghi A, Izadkhast P.S, and Kashani A.H, (2013). Applicability of graphite nanofluids in direct solar energy absorption. Sol Energy; 94:327-34.

[3] Moh'd A. Al-Nimr and Ameer Mohammed Abbas AlDafaie (2014). Using nanofluids in enhancing the performance of a novel two-layer solar pond. Energy, Volume 68, Pages 318-326.

[4] Taylor R.A, Phelan P.E, Otanicar T.P, Adrian R, and Prasher R,(2011). Nanofluid optical property characterization: towards efficient direct absorption solar collectors. Nanoscale Res Lett;6(255).

[5] Saidura R, Leongb K, and Mohammad H, (2011). A review on applications and challenges of nanofluids. Renew Sustain Energy Rev; 15:1646-68.

[6] Yousefi T, Veysi F, Shojaeizadeh E, andZinadini $S,(2012)$. An experimental investigation on the effect of Al2O3-H2O nanofluid on the efficiency of flat-plate solar collectors. Renew Energy; 39(1):293-8. 